Results The frequency of visits to the ?static? pages were as follows: news items (27\%), pharmacologic treatment (21\%), diagnostic/therapeutic guidelines (21\%), event broadcasts (12\%), disease-specific education (10\%), and nonpharmacologic management (8\%). Highlights of the ACR meetings were one of the most heavily accessed ?news item? postings on the Site. For the interactive forums, treatment related postings constituted the majority of postings: $55 \%$ of questions in ?Ask the Expert?, and $70 \%$ of postings to the Message Board. ?Hits? to the Site, and time spent on the Site, have increased steadily since launch, currently totalling $1,200,000$ hits and 12 min per month, respectively.

Conclusion The versatility of the Internet confers the unique ability to constantly update educational data bases. The desire for updated information is reflected on this Arthritis Web Site by the high frequency of visits to treatment and news related pages. Credible educational websites can effectively complement traditional on-site educational forums.

\section{Cytokines and inflammatory mediators}

\section{AB0009 TNF ALPHA AS A MARKER OF ARTICULAR INVOLVEMENT IN PATIENTS INFECTED WITH HIV}

GG Bagnato, C Romano, C Arrigo, G Chirico. Department of Internal Medicine, Division of Rheumatology, Policlinico Universitario, Messina, Sicily

\subsection{6/annrheumdis-2001.808}

Background In the last years great attention was given to the problems correlated to Hiv infection. The clinical rheumatologic manifestations correlated to Hiv infection generally are olygopolyarthritis, polyarthritis or Reiter Syndrome. The Hiv arthritis usually olygoarticular and asymmetric, involves the big articulations and it isn't correlate to Hla B27 aplotype. Some studies demonstrated an articular involvement in about $30 \%$ of the patients. Seems that the particular problems are correlated with a disregulation of the immune system with a sovraexpression of some pro-inflammatory cytokines.

Objectives Aim of this study was to evaluate the prevalence of rheumatologic manifestations in patients with Hiv infection and to evaluate if there was a correlation between articular involvement and sovraexpression of TNF alpha that is such important in articular omeostasis.

Methods We selected 46 patients with Hiv infetion, mean age 39 (22-59), 10 healthy subjects and 10 with rheumatoid arthritis as negative and positive controls. At the beginning of this study we did an articular evaluation with a questionnaire with 10 items regarding rheumatological problems in all the $\mathrm{Hiv}+$ patients.

Results We found rheumatologic manifestations in 11(24\%) and the most common was the presence of diffuse polyartralgias. Seric TNF alpha levels were increased in the Hiv group with articular involvement and was normal in those without articular involvement $(\mathrm{p}=0,02)$ but there weren't statistical differences between the 2 groups for CD4 count and viral load.

Conclusion TNF alpha seems to be a clear index of articular involvement in patients with HIV infection but doesn't seems to be correlated to viral load and progression of disease.

\section{AB0010 INCREASED COLLAGEN PRODUCTION BY HUMAN LUNG FIBROBLASTS IN THE RESPONSE TO TUMOUR NECROSIS FACTOR-RELATED APOPTOSIS-INDUCING LIGAND}

WV Yurovsky. Department of Medicine, University of Maryland, Baltimore, USA

\subsection{6/annrheumdis-2001.809}

Background Tumour necrosis factor-related apoptosis-inducing ligand (TRAIL), also called Apo-2 ligand, is a member of the TNF family that has been reported to induce apoptosis in a variety of transformed cell lines, as well as in normal human hepatocytes in vitro. Among the family members, TRAIL displays highest homology to CD95 ligand, receptor of which may not only mediate apoptosis of $\mathrm{T}$ cells, but also mediate the proliferation of normal human fibroblasts. Considering structural and functional similarities between TRAIL and CD95 ligand, we examined the effects of soluble TRAIL on normal human lung fibroblasts. Collagen a2(I) mRNA expression in fibroblasts was measured by RT-PCR, with ribosomal protein S9 as an internal standard. Normalised collagen mRNA expression was increased in fibroblasts stimulated with TRAIL for 1 or 7 days, with peak response ( $>5$-fold increase) at $10 \mathrm{ng} / \mathrm{ml}$ TRAIL. The increased expression of collagen a2(I) gene was confirmed by cDNA microarray that also revealed 72 other genes with expression level increased and 108 genes with expression level decreased a 2.2-fold in comparison with quiescent fibroblasts. There was little, if any, effect of TRAIL on fibroblast proliferation. The expression of TRAIL was also found in $\mathrm{CD} 8^{+} \mathrm{T}$ cell clones that had undergone oligoclonal expansion in the lungs of patients with systemic sclerosis (scleroderma) and were able to stimulate collagen production in lung fibroblasts in vitro. These data suggest that TRAIL can enhance collagen production by fibroblasts that are resistant to TRAIL-induced apoptosis.

Objectives

Methods

Results

Conclusion

\section{AB0011 THE ESTIMATION OF SYNOVIAL FLUID IMMUNOLOGICAL PARAMETERS IN RHEUMATOID ARTHRITIS}

VV Bazarniy, NS Petrovich, SV Tsvirenko, GA Tsaur. Laboratory Diagnostic, Ural State Medical Academy, Ekaterinburg, Russia

10.1136/annrheumdis-2001.810

\section{Background}

Objectives Laboratory synovial fluid (SF) tests are often held for joints condition, stage and acuteness of the inflammatory processes estimation. Immunological exams of SF is not routine procedure in clinical practice. We have studied the opportunity of immunological tests used in diagnostics of rheumatoid arthritis (RA).

Methods 44 patients (24 females and 20 males) with RA, diagnosed according to the American Colleges of Rheumatology criteries (1987) were examined. 29 of them have been seropositive. SF was taken by standard knee arthrocentesis. An immunological SF testing included determination of the levels of immunoglobulins A, M, G(IgA, IgM, IgG); C-reactive protein; circulating immune complex; complement proteins; interleukin-1beta (IL1beta) and tumour necrosis factor alpha TNF-alpha); rheumatoid factor (RF); phagocyte activity tests. These parameters were also determined in the venous blood of the RA patients. 